\title{
Pengelolaan dan Pemanfaatan Laboratorium Sekolah bagi Guru Muhammadiyah di Jakarta Timur
}

\author{
Susilo $^{1}$ dan Gufron Amirullah ${ }^{1}$ \\ ${ }^{1}$ Program Studi Pendidikan Biologi, FKIP, Universitas Muhammadiyah Prof. Dr. Hamka \\ Email: susilo@uhamka.ac.id
}

\begin{abstract}
Abstrak
Kegiatan Program Kemitraan Masyarakat (PKM) ini bertujuan untuk memberikan pengetahuan dan ketrampilan bagi guru Biologi SMA khususnya dan guru MIPA pada umumnya di sekolah swasta Muhammadiyah wilayah Jakarta Timur. Mitra dari kegiatan ini adalah guru-guru di sekolah Muhammadiyah yang tergabung dalam Dikdasmen Jakarta Timur. Materi yang diberikan antara lain pengelolaan laboratorium, praktik tekanan osmosis eritrosit, pengenalan alat lab dan maintenance mikroskop. Metode yang digunakan dalam kegiatan ini yaitu pemberian materi dan demonstrasi. Pemberian materi dilakukan dengan dua cara yaitu penyampaian materi secara klasikal dan penyampaian materi dengan praktik. Hasil yang diperoleh dari kegiatan ini adalah peningkatan pengetahuan dan skill para peserta. Para peserta merasa senang sekali menerima materi dan sangat antusias dengan adanya praktik secara langsung. Dapat disimpulkan bahwa kegiatan PKM pemanfaatan dan pengelolaan laboratorium bagi guru biologi tingkat SMA ini sangat bermanfaat.
\end{abstract}

Kata kunci: Laboratorium; Pengelolaan; Sekolah; SMA; Muhammadiyah

\begin{abstract}
This Community Partnership Program (PKM) activity aims to provide knowledge and skills for high school biology teachers and MIPA teachers in general at Muhammadiyah private schools in East Jakarta. Partners of this programs are teachers at Muhammadiyah schools who are members of Dikdasmen East Jakarta. Materials provided include laboratory management, erythrocyte osmosis pressure practice, lab tool introduction and microscope maintenance. The method used in this activity is the provision of materials and demonstrations. The giving of materials is done in two ways, namely the delivery of classical material and the delivery of material with practice. The result of this activity is the improvement of knowledge and skill of the participants. Participants were delighted to receive the material and were very enthusiastic about the practice directly. It can be concluded that the PKM utilization and laboratory management activities for high school biology teachers are very useful.
\end{abstract}

Keywords: Laboratory; Management; Muhammadiyah; Senior High School

Format Sitasi: Susilo \& Amirullah, G. (2018). Pengelolaan dan Pemanfaatan Laboratorium Sekolah bagi Guru Muhammadiyah di Jakarta Timur. Jurnal SOLMA, 07(1), 127-137.

Revisi: 28-01-2018; Diterima: 04-03-2018; Diterbitkan: 07-04-2018.

\section{PENDAHULUAN}

Menurut Peraturan Menteri Negara Pendayagunaan Aparatur Negara dan Reformasi Birokrasi No.03/Januari/2010 dan Peraturan Bersama Menteri Pendidikan Nasional dan Kepala Badan Kepegawaian Negara No.02 dan No.13/Mei/2010, yang dimaksud dengan Laboratorium Pendidikan adalah unit penunjang akademik pada lembaga pendidikan, berupa ruangan tertutup atau terbuka, bersifat permanen atau bergerak, dikelola secara 
sistematis untuk kegiatan pengujian, kalibrasi, dan/atau produksi dalam skala terbatas, menggunakan peralatan dan bahan berdasarkan metode keilmuan tertentu, dalam rangka pelaksanaan pendidikan, penelitian, dan pengabdian kepada masyarakat.

Laboratorium merupakan salah satu sarana penunjang kegiatan belajar mengajar disekolah. Di laboratorium ini peserta didik dapat melaksanakan praktek eksperimentasi, meneliti, membuktikan teori-teori yang didapatkan di buku dan sebagainya (Wirjosoemarto dkk., 2000). Laboratorium di sekolah ada banyak ragamnya, bergantung pada jurusan yang ada di sekolah tersebut. Pada sekolah-sekolah yang mempunyai jurusan IPA, tentu membutuhkan laboratorium IPA. Laboratorium IPA ini mempunyai sub-sub laboratorium biologi, fisika dan kimia. Biologi adalah ilmu hayati, yang prosesnya banyak dijumpai dalam kehidupan sehari-hari (Rustaman, 1996). Maka dari itu untuk meningkatkan pemahaman materi biologi, keberadaan laboratorium biologi menjadi sesuatu yang harus ada di sekolahan yang mempunyai jurusan IPA.

Laboratorium merupakan ujung tombak dalam proses pengembangan dan penyebaran ilmu pengetahuan sehingga keberadaan laboratorium tersebut perlu didukung dengan tenaga laboran yang profesional. Karena itu, tenaga laboratorium sebagai salah satu komponen yang dominan terhadap perkembangan dan bahkan kemunduran suatu laboratorium. Tenaga laboratorium sekolah merupakan salah satu tenaga kependidikan yang sangat diperlukan untuk mendukung peningkatan kualitas proses pembelajaran di sekolah melalui kegiatan laboratorium. Sebagaimana tenaga kependidikan lainnya, tenaga laboratorium sekolah juga merupakan tenaga fungsional yang harus memiliki skill dan kompetensi di bidangnya.

Hambatan berikutnya adalah belum ada tenaga laboratorium baik itu kepala, laboran maupun teknisi yang memang benar-benar ahli di bidang pengelolaan laboratorium karena tenaga laboran di laboratorium IPA hanyalah satu orang yang kadang merangkap dalam mengelola semua laboratorium IPA yang ada di sekolah itu. Hal ini terjadi karena kurangnya sumber daya manusia dan sumber dana di lingkungan sekolah terutama sekolah-sekolah swasta.

Peraturan Menteri Pendidikan Nasional Nomor 26 Tahun 2008 tentang Standar Tenaga Laboratorium Sekolah/Madrasah telah menetapkan kompetensi dan subkompetensi bagi Kepala Laboratorium, Teknisi Laboratorium, dan Laboran Laboratorium Sekolah/Madrasah. Empat kompetensi utama yang harus dipenuhi sebagai seorang laboran 
atau teknisi sebagaimana yang tercantum dalam Permen tersebut adalah: 1) Kompetensi Kepribadian, 2) Kompetensi Sosial, 3) Kompetensi Administratif, 4) Kompetensi Profesional. Mengingat hal tersebut maka kompentensi tenaga laboratorium perlu ditingkatkan seiring dengan kemajuan ilmu pengetahuan dan teknologi antara lain melalui pelatihan-pelatihan sebagai wahana peningkatan wawasan dan skill tenaga laboratorium sekolah/madrasah.

Menindaklanjuti Permendiknas Nomor 26 Tahun 2008, pemerintah melalui Direktorat Tenaga Kependidikan sedang mengembangkan sistem pendidikan dan latihan bagi tenaga laboratorium. Namun progam tersebut belum berjalan maksimal dan belum terealisasi secara merata. Menyikapi permasalahan tersebut, melalui PKM pengembangan ketrampilan melalui pelatihan tenaga laboratorium biologi dengan bekerja sama dengan dinas pendidikan Jakarta Timur adalah kegiatan yang sangat penting dan membantu pemerintah dalam rangka mewujudkan Permendiknas tersebut. Adapun sasaran kegiatan ini adalah guru IPA dan tenaga laboratorium di sekolah/madrasah di wilayah Jakarta.

Konsep dari kegiatan PKM ini adalah memberikan pelatihan mengenai cara pengelolaan laboratorium agan berfungsi sebagaimana mestinya sehingga keberadaan laboratorium tersebut menjadi lebih efektif, misalnya mulai dari cara inventarisasi alat, penggunaan alat dan ketrampilan pembuatan awetan seperti herbarium, taksidermi maupun preparat mikroskopis. Selain itu, dalam kegiatan PKM ini juga perlu diberikan/diperkenalkan peralatan-peralatan terbaru dan cara penggunaannya serta cara merawat dan melakukan perbaikan atau service. Hal-hal tersebut dirasa perlu diberikan mengingat tuntutan profesionalisme sebagai tenaga laboratorium harus memiliki banyak keahlian dibidangnya. Berdasarkan permasalahan yang telah dikemukakan di atas, maka Program Studi Pendidikan Biologi FKIP UHAMKA memiliki peran strategis untuk membantu meningkatkan kompetensi guru sekaligus menjadi media promosi bagi Program Studi Pendidikan Biologi FKIP UHAMKA.

\section{MASALAH}

Hambatan yang muncul dalam Permendiknas tersebut salah satunya adalah masih sedikitnya tempat/instansi pemerintah yang menyelenggaran program pelatihan ketrampilan (skill) bagi tenaga laboratorium khususnya laboratorium biologi. Selain itu, kurangnya informasi pelatihan dari Diknas menyebabkan guru/tenaga laboran tidak mengetahui adanya pelatihan yang diadakan. Akibatnya tidak semua guru/tenaga laboran 
tersebut mendapatkan kesempatan pelatihan laboratium. Sehingga kompetensi tenaga laboratorium di sekolah baik guru yang merangkap sebagai kepala laboratorium maupun laboran dan teknisi laboratorium masih kurang.

Hambatan berikutnya adalah belum ada tenaga laboratorium baik itu kepala, laboran maupun teknisi yang memang benar-benar ahli di bidang pengelolaan laboratorium karena tenaga laboran di laboratorium IPA hanyalah satu orang yang kadang merangkap sebagai tenaga pengajar atau guru dalam mengelola semua laboratorium IPA yang ada di sekolah itu. Hal ini terjadi karena kurangnya sumber daya manusia dan sumber dana di lingkungan sekolah terutama sekolah-sekolah swasta.

Beberapa permasalahan tersebut kemudian dirumuskan lebih lanjut berdasarkan hasil kesepakatan antara Tim PKM Prodi Pendidikan Biologi UHAMKA bersama mitra untuk mendapatkan perioritas yang harus ditangani, sebagai berikut:

a. Perlu diberikannya pengembangan pengetahuan kepada tenaga laboratorium tentang pengelolaan laboratorium yang baik dan benar.

b. Perlu adanya penambahan pelatihan ketrampilan bagi tenaga laboratorium ataupun guru tentang kegiatan praktikum yang bisa diterapkan di tingkat sekolah.

Berlandaskan uraian di atas, maka yang menjadi prioritas kegiatan ini adalah guruguru mata pelajaran khususnya guru biologi yang tergabung dalam Dikdasmen Jakarta. Sasaran utama dari prioritas kegian PKM ini adalah sekolah-sekolah Muhammadiyah yang jarak lokasinya dekat dengan kampus UHAMKA di Pasar Rebo Jakarta Timur.

Adapun tujuan pendidikan dan pelatihan ini adalah: 1) meningkatkan pengelolaan layanan laboratorium bagi tenaga laboratorium khususnya teknisi dan laboran yang berada di sekolah guna menunjang kelancaran PBM di kelas berdasarkan kurikulum yang diterapkan agar sesuai dengan tujuan yang hendak dicapai. 2) membekali peserta dengan kemampuan dalam mengelola laboratorium sekolah/madrasah, sehingga peserta dapat mengelola laboratorium berkaitan dengan fungsi manajer yakni perencanaan, penataan, administrasi, pengamanan, perawatan dan pengawasan. 3) membekali peserta dengan berbagai ketrampilan khususnya yang berkaitan dengan kegiatan laboratorium agar fungsi dan kedudukan laboratorium di sekolah bisa dimanfaatkan secara optimal.

\section{SOLUSI}

Berdasarkan permasalahan yang telah dikemukakan di atas, maka pendidikan dan pelatihan untuk meningkatkan kompetensi laboran dan teknisi laboratorium sangat 
diperlukan. Hal ini disebabkan karena masih rendahnya tingkat pengetahuan dan skill tentang pengelolaan dan pemanfaatan laboratorium. Sehingga bukan rahasia umum lagi bahwa laboratorium sekolah yang dibangun dengan biaya yang sangat mahal banyak yang kurang dimanfaatkan secara optimal dalam pembelajaran. Merujuk dari permasalahan di atas, diperlukan pendidikan dan pelatihan kepada anak tenaga laboratorium khususnya laboran dan teknisi untuk bersedia secara sadar meningkatkan kemampuan dan ketrampilan dasar tentang laoratorium agar fungsi dan kedudukan laboratorium di sekolah tersebut dapat dimanfaatkan secara optimal.

Adapun pelatihan ketrampilan yang akan diberikan kepada tenaga laboratorium sekolah antara lain :

a. Pengetahuan kompentensi bagi kepala laboratorium, teknisi dan laboran

b. Pengelolaan laboratorium (management plan), mencakup langkah-langkah perencanaan, pengaturan, pemeliharaan, pengadministrasian, penganggaran dan keselamatan laboratorium

c. Pelatihan ketrampilan (life skill), memberikan ketrampilan kepada tenaga laboratorium dan guru yang mencakup pembuatan preparat, percobaan beberapa praktikum biologi di sekolah, perawatan dan service mikroskop.

Adapun upaya untuk menyelesaikan permasalahan yang dihadapi oleh tenaga laboratorium dapat dilakukan langkah-langkah pengembangan dan pelatihan laboratorium, dengan ketentuan :

a) Penyampaian materi teori disampaikan secara klasikal

b) Penyampaian materi ketrampilan dalam bentuk praktek/demonstrasi

c) Komposisi penyajian Teori dan Praktek adalah masing-masing 40 \%: $60 \%$

d) Proses pembelajaran didukung dengan media belajar dan modul yang memadai.

\section{METODE PELAKSANAAN}

\section{Tahap Perencanaan}

Berdasarkan permasalahan yang kerap kali dihadapi oleh tenaga laboran dan guru mata pelajaran IPA di sekolah Muhammadiyah di Jakarta, berikut merupakan tahapan yang akan dilakukkan:

a. Mengidentifikasi skill/kemampuan tenaga laboratorium yang sudah ada.

b. Memberikan pengetahuan tambahan terkait pengelolaan laboratorium dan penggunaan peralatan laboratorium. 
c. Memberikan pelatihan dalam bentuk praktek langsung kepada guru-guru mata pelajaran IPA dan tenaga laboratorium.

\section{Tahap pelaksanaan}

Kegiatan PKM ini dilaksanakan selama 2 hari pelaksanaan yang bertempat di Laboratorium Biologi FKIP UHAMKA. Namun sebelum pelaksanaan, tim mengundang peserta baik guru-guru mata pelajaran IPA maupun laboran di sekolah-sekolah Muhammadiyah se-Jakarta Timur ke Laboratorium Biologi FKIP UHAMKA. Merujuk dari solusi yang ditawarkan, berikut adalah langkah-langkah yang dilakukan:

\section{Hari pertama:}

Pada hari pertama, para peserta diberikan materi tentang pentingnya manajemen laboratorium. Hal ini sangat penting karengan sebagai dasar dalam memaksimalkan laboratorium yang sudah ada disekolah. Penyampaian materi diberikan oleh Gufron Amirulloh, M.Pd secara klasikal pada sesi pertama yang bertempat di laboratorium biologi FKIP UHAMKA. Pada sesi kedua, para peserta diberikan pelatihan praktikum tentang osmosis. Materi tersebut sebagai materi tambahan dalam kegiatan praktek disekolah. Materi akan diberikan oleh Yuni Astuti, M.Pd.

\section{Hari kedua:}

Hari kedua diisi dengan pemberian pelatihan penggunaan alat lapanagan. Materi ini perlu disampaikan guna mendukung kegiatan lapangan yang akan dilakukkan oleh siswa. Penyampaian materi akan dilakukkan oleh Hilman Faruq, M.Pd pada sesi pertama. Pada sesi kedua, para peserta diberikan pelatihan perawatan alat lab dan maintenence mikroskop. Materi ini berguna untuk membantu guru dan laboran dalam merawat dan memperbaiki peralatan laboratorium. Penyampaian materi akan dibawakan oleh Susilo, M.Si.

\section{Tahap Evaluasi}

Tahap evaluasi dilakukan satu hari setelah kegiatan pelatihan selesai. Evaluasi yang dilakukan pada kegiatan pengabdian masyarakat ini adalah evaluasi kegiatan terhadap perencanaan dan pelaksanaan. Evaluasi perencanaan bertujuan untuk menilai tingkat persiapan kegiatan pengabdian masyarakat. Adapun hasil evaluasi persiapan meliputi penyampain undangan kepada peserta dan pemilihan hari dan waktu kegiatan. Sementara evaluasi pelaksanaan bertujuan untuk menilai pencapaian target acara dengan indikator 
penilaian terdiri dari: jumlah peserta, ketepatan waktu pelatiahan, kesesuaian acara kegiatan; kepuasan peserta terhadap penyampaian materi, minat peserta; dan ketanggapan panitia. Setelah evaluasi selesai dilaksanakan, dilanjutkan dengan menyusun laporan pertanggungjawaban kegiatan pengabdian masyarakat.

\section{HASIL DAN PEMBAHASAN}

\section{Peningkatan kemampuan pengelolaan laboratorium}

Pelaksanaan kegiatan Pelatihan Laboratorium Bagi Guru SMA berlangsung pada hari Senin, 20 Desember 2017 dari jam 08.00 WIB s.d 16.00 WIB, dengan dihadiri 26 orang peserta, guru-guru biologi SMA yang tergabung dalam Dikdasmen Jakarta Timur. Kegitan diawali dengan penyampaikan materi pertam oleh bapak Gufron Amirullah, M.Pd yang menjelaskan tentang pentingnya mengelola laboratorium.

Pemateri menjelaskan bahwa laborataorium yang baik akan membantu sekali dalam proses belajar, oleh sebab itu para guru mata pelajaran ataupun laboran harus bias merancang pengelolaan laboratorium yang baik. Suatu laboratorium yang baik harus memiliki sistem organisasi yang baik, uraian kerja (job description) yang jelas, pemanfaatan fasilitas yang disiplin, efektif, efisien serta administrasi lab yang baik. Menurut pak Gufron, Pengeloaan yang dimaksud adalah kegiatan yang dimulai dari perencanan, pengaturan, pemeliharaan, pengadministrasian, penganggaran dan keselamatan. Beliau juga menambahkan bahwa suatu laboran itu harus memenuhi standar yang baik sebagai mana di atur dalam Permen No. 26 tahun 2008 .

Suatu laboratorium agar dapat berfungsi dengan baik untuk menunjang proses pembelajaran memerlukan perencanaan yang matang. Perencanaan pengadaan peralatan dan bahan adalah suatu hal yang sangat penting, karena akan berakibat pada dapat berlangsung atau tidaknya praktikum dikemudian hari. Langkah perencanaan dapat dilaksanakan dalam tahapan berikut:

1. Identifikasi

Tahapan ini adalah langkah awal untuk mencoba mengidentifikasi alat dan bahan apa saja yang dibutuhkan oleh setiap mata pelajaran yang akan melaksanakan praktek laboratorium. Langkah ini idealnya dilakukan bersama guru-guru yang akan menggunakan laboratorium untuk kegiatan praktek.

2. Pemilihan Alat 
Dari hasil identifikasi peralatan dan bahan untuk kegiatan praktek laboratorium baru dapat ditentukan mengenai jenis alat yang dibutuhkan, tetapi karakteristik alat dan bahan yang dimaksud belum dapat ditentukan secara tepat. Oleh karena itu diperlukan kemampuan untuk merencanakan memilih spesifikasi peralatan yang tepat. Spesifikasi alat umumnya berhubungan dengan: bentuk, ukuran (dimensi), akurasi, batas-batas kemampuan, sumber daya (untuk peralatan fisika/listrik) dan bahan yang digunakan.

Ketika merencanakan pengajuan alat, haruslah didasarkan pada kebutuhan, bukan mengacu pada yang tersedia pada katalog atau brosur penawaran barang. Hal ini bukan berarti tidak boleh memilih apa yang ada di dalam catalog, tetapi harus diutamakan kebutuhannya. Kesalahan menentukan spesifikasi alat mengakibatkan biaya investasi menjadi tinggi. Karena praktikum bertujuan memvisaulisasikan suatu proses atau fenomena yang abstrak menjadi konkrit dan berlatih untuk melakukan pengukuran, dalam praktikum tingkat sekolah menengah tidak diperlukan peralatan yang memiliki akurasi yang sangat baik setara dengan peralatan untuk penelitian atau riset perguruan tinggi.

3. Membuat daftar usulan alat

Apabila sudah dapat ditentukan spesifikasi alat yang diperlukan maka selanjutnya adalah menyusun daftar usulan alat laboratorium. Usulan daftar alat laboratorium dimaksudkan untuk memudahkan dalam meneliti dan menentukan anggaran. Usulan alat laboratorium harus menyatakan spesifikasi yang jelas mengenai alat yang diusulkan, serta jumlah satuan yang diperlukan dan harga satuan sehingga memperkecil kesalahan dalam proses pengadaan.

4. Perencanaan Usulan Bahan Kimia

Bahan-bahan kimia biasanya dibuat dalam beberapa tingkat kemurnian. Gradasi tingkat kemurnian mulai dari sangat murni hingga kemurnian dengan nilai tertentu. Tingkat kemurnian yang tinggi biasanya digunakan untuk penelitian, sementara untuk kegiatan praktikum sekolah tidak diperlukan bahan kimia murni. Semakin tinggi tingkat kemurnian bahan kimia proses penyediaannya semakin sulit, hal ini berakibat pada harga bahan kimia tersebut semakin mahal. 
Dalam kegiatan praktikum sekolah bahan kimia dalam tingkatan teknis sudah memadai. Dengan memilih bahan kimia tingkat teknis biaya pembelian bahan dapat dihemat lebih dari 50\%, namun apabila biaya memungkinkan dapat menggunakan bahan kimia dengan tingkat kemurnian lebih tinggi. Meskipun demikian dalam kegiatan praktikum sekolah penggunaan bahan kimia murni tidak memberikan pengaruh yang signifikan terhadap hasil kerja praktek. Bahan kimia teknis cocok untuk laboratorium sekolah karena harganya lebih murah daripada bahan-bahan analitik. Menggunakan bahan kimia dengan tingkat kemurnian tinggi untuk keperluan praktikum merupakan pemborosan.

\section{Praktek toleransi osmotik eritrosit}

Pada pelatihan ini, para peserta dibagi dalam 4 kelompok terdiri dari 3-5 orang anggota. Setiap kelompok melakukan praktek langsung setelah diberikan penjelasan oleh tim instruktur. Materi yang diberikan adalah toleransi osmotic eritrosit. Pada sesi ini para peserta praktek secara langsung yang di pandu oleh nara sumber yaitu ibu Yuni Astuti, MPd.

\section{Perawatan peralatan laboratorium dan praktek service mikroskop}

Pada materi ini, para guru diberikan pemahaman tentang mikroskop. Hal pertama yang diberikan adalah terkait prinsip dan cara kerja mikroskop. Dengan menggunakan contoh mikroskop yang ada pak Susilo, M.Si menjelaskan bagia-bagian mikroskop dan fungsinya sehingga para peserta dapat melihat langsung bagian-bagian dalam serta fungsinya masing-masing. Hal ini penting dilakukkan karena sebagai modal awal dalam pemeliharaannya. Apabila peserta sudah mengetahui bagian dan fungsinya maka para peserta diharapkan tidak takut lagi terhadap penggunaan dan penanganan mikroskop yang rusak. Selain itu, para peserta juga diberikan pengenalan terhadap ala-alat lab yang baru seperti usb mikroskop dan pemanfaatan smartphone dalam belajar di laboratorium. Kegitan pengabdian ini memiliki relevansi dengan kebutuhan guru dalam mengajar di laboratorium. Mengingat sekarang semua siswa sudah memiliki smartphone.

\section{Pembahasan}

Laboratorium sebagai fasilitas belajar dalam Pengembangan Sistem Pendidikan Tenaga Kependidikan Abad ke 21 (SPTK-21, Depdiknas, 2002) merupakan tempat yang digunakan untuk mengaplikasikan teori keilmuan, pengujian teoritis, pembuktian 
uji coba, penelitian dan sebagainya dengan menggunakan alat bantu yang menjadi kelengkapan dari fasilitas dengan kuantitas dan kualitas yang memadai.

Kegitan pengabdian ini memiliki relevansi dengan kebutuhan guru saat mengajar di laboratorium. Berdasarakan hasil survey sebelum pelaksanaan, guru-guru biologi atau MIPA dalam mengelola laboratorium. Mereka umumnya masih keterbatasan ketrampilan dalam menggunakan semua peralatan yang ada di laboratorium. Selain itu, masalah lainnya adalah masih terbatasnya sarana dan prasarana laboratorium yang tersedia di sekolah mereka.

Beberapa faktor yang mendukung terlaksananya kegiatan pengabdian pada masyarakat ini adalah besarnya minat dan antusiasme peserta selama kegiatan, sehingga kegiatan berlangsung dengan lancar dan efektif. Sedangkan faktor penghambatnya adalah keterbatasan waktu lokakarya serta masih kurangnya ketersediaan alat-alat laboratorium biologi di sekolah untuk merealisasikan hasil kegiatan pasca pelatihan ini. Dari hasil kegiatan ini tim melakukan tanya jawab terkait pengelolaan lab di sekolah masing-masing. Berdasarkan observasi tersebut, tim menyimpulkan bahwa pemakaian atau pemanfaatan lanoratorium di sekolah SMA Muhammadiyah belum optimal. Masalah tersebut disebabkan oleh berbagai faktor antara lain:

a. Kemampuan dan penguasaan guru terhadap peralatan dan pemanfaatan bahan praktek masih belum memadai.

b. Kurang memadai baik secara kualitas maupun kuantitas tenaga laboratorium.

c. Banyak alat-alat laboratorium dan bahan yang sudah rusak yang belum diadakan kembali

d. Tidak cukupnya/terbatasnya alat-alat dan bahan mengakibatkan tidak setiap siswa mendapat kesempatan belajar untuk mengadakan eksperimen.

Berdasarkan wawancara, tanya jawab dan pengamatan langsung selama kegiatan berlangsung, kegiatan pelatihan ini memberikan hasil sebagai berikut:

a. Meningkatnya pengetahuan dan pemahaman guru biologi SMA dalam merancang dan membuat media pembelajaran biologi.

b. Meningkatnya keterampilan guru biologi SMA dalam pembuatan preparat awetan biologi, sehingga dimungkinkan peserta dapat membuat sendiri preparat biologi di sekolah. 


\section{KESIMPULAN}

Dari kegiatan pelatihan ini dapat disimpulkan bahwa: Pengetahuan dan pemahaman guru biologi SMA dalam merancang dan mengelola Laboratorium biologi masih kurang dan perlu mendapatkan pelatihan lagi dengan materi yang berbeda

\section{UCAPAN TERIMA KASIH}

Ucapan terima kasih kami tujukan kepada pemberi dana kegiatan LPPM UHAMKA. Kami juga menyapaikan terima kasih kepada pihak-pihak yang membantu pelaksanaan kegiatan.

\section{DAFTAR PUSTAKA}

--------. 2008. Peraturan Menteri Pendidikan Nasional Republik Indonesia No.mor 26 Tahun 2008 tentang Standar Tenaga Laboratorium Sekolah/Madrasah.

Depdiknas. (2005). Profil Laboran. Jakarta: Dit. Tendik, Ditjen PMPTK

Depdiknas. (2006). Sistem Pendidikan Nasional. Jakarta: Depdiknas.

Depdiknas. (2007). Standar Kompetensi, Kualifikasi, dan Sertifikasi Tenaga Laboratorium Sekolah. Jakarta: Depdiknas.

Millar, R. 2004. The Role of Practical Work in The Teaching and Learning of Science. Washington: University of York.

Rustaman, Nuryani. 1996. Pengelolaan Laboratorium Biologi. Makalah pelatihan Pengelolaan Laboratorium PMIPA LPTK Bidang Biologi.

Supriatno, B., Rustaman, N., Redjeki, S.,,dan Sudargo,.F., 2009. Uji Langkah Kerja Laboratorium Biologi Sekolah. Proceding Seminar Nasional Jurusan Pendidikan Biologi.

Dirjen Dikti. (2003). Sistem Perencananaan, Penyusunan Program dan Penganggaran.

Wirjosoemarto, Koesmadji. Adisendjaja, Y.H., Supriatno, B. Riandi. (2000). Teknik Laboratorium. Bandung. UPI. 